\title{
HUBUNGAN APLIKASI CASEIN PHOSPHOPEPTIDE AMORPHOUS CALCIUM PHOSPHATE (CPP-ACP) TERHADAP REMINERALISASI GIGI
}

\author{
Busman ${ }^{*}$, Utmi Arma ${ }^{* *}$, Nofriadi ${ }^{* * *}$ \\ Bagian Oral Biologi, FKG, Universitas Baiturrahmah, Padang \\ ${ }^{* *}$ Bagian Penyakit Mulut, FKG, Universitas Baiturrahmah, Padang \\ ${ }^{* * *}$ Mahasiswa FKG, Universitas Baiturrahmah, Padang
}

\section{KATA KUNCI}

Casein Phosphopeptide

Amorphous Calcium

Phosphate (CPP-ACP),

Remeneralisasi, Gigi.

\begin{abstract}
ABSTRAK
Casein Phosphopeptide Amorphous Calcium Phosphate (CPP-ACP) merupakan bahan yang dapat memperkuat dan meremineralisasi gigi serta membantu mencegah karies gigi. Peneliti tertarik melakukan penelitian tentang aplikasi CPP-ACP terhadap remineralisasi enamel gigi. Jenis penelitian ini adalah eksperimental laboratoris dengan menggunakan penelitian analityc experimental pretest and postest design. Sampel yang digunakan pada penelitian ini adalah gigi premolar yang telah diekstraksi dengan teknik selected sampling. Penelitian ini terdiri dari 3 perlakuan dimana setiap perlakukan menggunakan 10 gigi. Hasil penelitian menunjukkan perbedaan ratarata berat gigi sebelum dan sesudah perendaman 1,2, 3, 4 dan 5, yaitu dengan hasil berturut-turut: konsentrasi $10 \% 0,0120 \mathrm{~g}, 0,0087 \mathrm{~g}$, $0,0078 \mathrm{~g}, 0,0052 \mathrm{~g}, 0,0030 \mathrm{~g}$, konsentrasi $20 \% 0,0134 \mathrm{~g}, 0,0097 \mathrm{~g}$, $0,0091 \mathrm{~g}, 0,0051 \mathrm{~g}, 0,0026 \mathrm{~g}$, dan konsentrasi $30 \% 0,0162 \mathrm{~g}, 0,0105 \mathrm{~g}$, $0,0088 \mathrm{~g}, 0,0058 \mathrm{~g}, 0,0030 \mathrm{~g}$. Hasil penelitian menunjukan berat gigi sebelum dan sesudah perendaman larutan CCP-ACP selama perendaman 1, 2, 3, 4 dan 5 menunjukkan perbedaan yang bermakna $(\mathrm{p}<0,05)$ antara berat gigi sebelum dan setelah dilakukan perendaman. Berdasarkan hasil di atas dapat disimpulkan bahwa semakin lama waktu perendaman gigi di dalam larutan CCP-ACP 30\% maka semakin tingginya penambahan berat gigi.
\end{abstract}

\section{PENDAHULUAN}

Karies gigi merupakan penyakit yang paling banyak dijumpai di rongga mulut. Penyakit ini terjadi karena demineralisasi jaringan permukaan gigi oleh asam organik yang berasal dari makanan yang mengandung asam. Karies akan membuat gigi menjadi rapuh. Gigi yang lebih rapuh tentunya akan lebih rentan terhadap demineralisasi sehingga kerusakan gigi yang terjadi akan semakin parah. ${ }^{1}$

Remineralisasi dapat mencegah terjadinya demineralisasi pada enamel gigi ketika level flouride rendah. Casein Phosphopeptide Amorphous Calcium Phosphate (CPP-ACP) merupakan bahan yang dapat memperkuat dan meremineralisasi gigi serta membantu mencegah karies gigi.

Casein phosphopeptide (CPP) memiliki kemampuan untuk menstabilkan ion kalsium, fosfat dan fluoride dalam keadaan amorf non-kristalin yang diperlukan pada enamel gigi. $^{2}$

Aplikasi topikal CPP-ACP menimbulkan reaksi kimia, yaitu CPP-ACP bereaksi dengan glikoprotein saliva yang melapisi 
permukaan gigi (dikenal sebagai pelikel saliva). Kalsium dan fosfat dalam bentuk amorphous (ACP) yang tidak terikat kuat pada pelikel saliva akan larut ke lingkungan sekitar gigi (saliva dan plak). CPP-ACP juga bereaksi secara kimia dengan kristal hidroksiapatit enamel dan dentin, mengikat gugus hidroksil dan membentuk kalsium fosfat hidroksiapatit yang tahan terhadap demineralisasi asam. ${ }^{3,4}$.

CPP-ACP mampu memperbaiki white spot dengan cara menggantikan kalsium dan fosfat gigi yang hilang akibat proses demineralisasi. Selanjutnya, sebagian kalsium dan fosfat dari CPP-ACP akan berdifusi menuju lingkungan sekitar gigi. Apabila kalsium dan fosfat dalam gigi white spot sudah cukup tergantikan maka kelebihan kalsium dan fosfat tersebut akan berdifusi menuju lingkungan sekitarnya ${ }^{5,6}$.

Penelitian Vashisht dkk menganjurkan untuk menerapkan pemakaian topikal CPP-ACP pasta tiga kali sehari selama 14 hari. Hasil menunjukkan adanya remineralisasi enamel. Tujuan penilitian ini adalah untuk mengetahui hubungan aplikasi Casein Phosphopeptide Amorphous Calcium Phosphate (CPP-ACP) terhadap remineralisasi gigi.

\section{METODE PENELITIAN}

Penelitian ini dilakukan di Laboratorium Kimia Kopertis Wilayah X Padang pada tanggal 8 Oktober 2013 sampai 23 Oktober 2013. Adapun alat-alat yang digunakan dalam penelitian ini adalah timbangan digital, kaca arloji, gelas ukur, elemeyer, shaker rotary, oven, kertas label, pinset, masker, sarung tangan, glass plate, alat tulis dan kalkulator sedangkan bahan yang digunakan adalah gigi premolar 1 atau 2 boleh atas atau bawah, asam phosfat 37\% dan Casein Phosphopeptide Amorphous Calcium Phosphate konsentrasi 10\%, 20\% dan $30 \%$.

Tahapan pertama dilakukan pembuatan white spot pada sampel yaitu gigi premolar sebanyak 30 buah kemudian masing-masing sampel diberi asam phosfat konsentrasi 37\% selama 20 menit agar terbentuk white spot buatan pada gigi. Kemudian sampel dikeringkan menggunakan oven dan ditimbang sebelum dilakukan perendaman. Perendaman sampel pada penelitian ini dibagi ke dalam 3 kelompok yaitu: kelompok 1, direndam dalam Casein Phosphopeptide Amorphous Calcium Phosphate konsentrasi $10 \%$. Kelompok 2, direndam dalam Casein Phosphopeptide Amorphous Calcium Phosphate konsentrasi 20\% sedangkan kelompok 3, direndam dalam Casein Phosphopeptide Amorphous Calcium Phosphate konsentrasi 30\%. Perendaman sampel ini dilakukan sebanyak 5 kali dengan cara di shaker $60 \mathrm{rpm}$ dalam Casein Phosphopeptide Amorphous Calcium Phosphate dimana masing-masing perendaman selama 1 jam.

Kemudian dilakukan penimbang an berat gigi setelah dilakukan perendaman Casein 
Phosphopeptide Amorphous Calcium Phosphate, gigi dikeringkan dengan oven, ditimbang lagi untuk mengetahui berat setelah dilakukan perendaman dan dicatat hasilnya dan dibandingkan hasilnya dengan berat awal sebelum dilakukan perendaman

\section{HASIL PENELITIAN}

Tabel 1. Rata-rata Penambahan Berat Pada Kandungan CPP-ACP 10\%, $20 \%$, dan 30\%

\begin{tabular}{lccc}
\hline \multicolumn{1}{c}{ CPP-ACP } & $10 \%$ & $20 \%$ & $30 \%$ \\
\hline Rata-rata berat awal & $\begin{array}{c}1,2194 \\
\mathrm{~g}\end{array}$ & $1,2527 \mathrm{~g}$ & $1,1193 \mathrm{~g}$ \\
$\begin{array}{l}\text { Perubahan berat } \\
\text { setelah perendaman 1 }\end{array}$ & $\begin{array}{c}0,0120 \\
\mathrm{~g}\end{array}$ & $0,0134 \mathrm{~g}$ & $0,0162 \mathrm{~g}$ \\
$\begin{array}{l}\text { Perubahan berat } \\
\text { setelah perendaman 2 }\end{array}$ & $\begin{array}{c}0,0087 \\
\mathrm{~g}\end{array}$ & $0,0097 \mathrm{~g}$ & $0,0105 \mathrm{~g}$ \\
$\begin{array}{l}\text { Perubahan berat } \\
\text { setelah perendaman 3 }\end{array}$ & $\begin{array}{c}0,0078 \\
\mathrm{~g}\end{array}$ & $0,0091 \mathrm{~g}$ & $0,0088 \mathrm{~g}$ \\
$\begin{array}{l}\text { Perubahan beratsetelah } \\
\text { perendaman 4 }\end{array}$ & $\begin{array}{c}0,0052 \\
\mathrm{~g}\end{array}$ & $0,0051 \mathrm{~g}$ & $0,0058 \mathrm{~g}$ \\
$\begin{array}{l}\text { Perubahan berat } \\
\text { setelah perendaman 5 }\end{array}$ & $\begin{array}{c}0,0030 \\
\mathrm{~g}\end{array}$ & $0,0026 \mathrm{~g}$ & $0,0030 \mathrm{~g}$ \\
$\begin{array}{l}\text { Rata-rata penambahan } \\
\text { berat gigi setelah 5 } \\
\text { kali perendaman }\end{array}$ & 0,0073 & $0,00798 \mathrm{~g}$ & 0,00886 \\
\hline
\end{tabular}

Berdasarkan tabel 1 dapat dilihat bahwa terjadi peningkatan nilai rata-rata berat gigi antara sebelum dan sesudah perendaman dengan larutan CPP-ACP 10\% yaitu pada sebelum perendaman rata-rata berat awal gigi $1,2194 \mathrm{~g}$ dan rata-rata berat gigi selama perendaman $1,2,3,4$ dan 5 terjadi penambahan berat sebesar $0,0120 \mathrm{~g}, 0,0087$ g, 0,0078 g, 0,0052 g dan 0,0030 g. Demikian juga dengan larutan CPP-ACP $20 \%$ yaitu pada sebelum perendaman ratarata berat awal gigi $1,2527 \mathrm{~g}$ dan rata-rata berat gigi selama perendaman 1, 2, 3, 4 dan 5 terjadi penambahan nilai rata-rata berat gigi antara sebelum dan sesudah perendaman yaitu sebesar 0,0134 g, 0,0097g, 0,0091 g,
0,0051 g, dan 0,0026 g. Sama halnya dengan larutan CPP-ACP 30\% yaitu pada sebelum perendaman rata-rata berat awal gigi 1,1193 $\mathrm{g}$ dan rata-rata berat gigi selama perendaman 1, 2, 3, 4 dan 5 terjadi penambahan berat gigi sebesar 0,0162g, 0,0105g, 0,0088g, 0,0058 dan 0,0030 .

Tabel 2 : Uji T-Paired Berat Gigi Sebelum dan Setelah Perendaman $10 \%$

\begin{tabular}{l|c|c}
\hline \multicolumn{1}{c|}{ Variabel } & Mean & P Value \\
\hline $\begin{array}{l}\text { Sebelum Perendaman - Setelah } \\
\text { perendaman 1 }\end{array}$ & 0.0120 & 0.000 \\
$\begin{array}{l}\text { Sebelum Perendaman - Setelah } \\
\text { perendaman 2 }\end{array}$ & 0.0087 & 0.000 \\
$\begin{array}{l}\text { Sebelum Perendaman - Setelah } \\
\text { perendaman 3 } \\
\text { Sebelum Perendaman - Setelah } \\
\text { perendaman 4 }\end{array}$ & 0.0078 & 0.000 \\
$\begin{array}{l}\text { Sebelum Perendaman - Setelah } \\
\text { perendaman 5 }\end{array}$ & 0.0030 & 0.000 \\
\hline
\end{tabular}

Dari tabel 2 dapat dilihat bahwa pada hasil uji $\mathrm{T}(\alpha=0,05)$, berat gigi sebelum dan sesudah perendaman larutan CPP-ACP 10\% selama perendaman $1,2,3,4$ dan 5 menunjukkan perbedaan yang bermakna $(\mathrm{p}<0,05)$ antara berat gigi sebelum dan setelah dilakukan perendaman. Berdasarkan hasil di atas dapat disimpulkan bahwa semakin lama waktu perendaman gigi di dalam larutan CPP-ACP 10\% maka semaikn tingginya penambahan berat gigi.

Tabel 3 : Hasil Uji T-Paired Berat Gigi Sebelum dan Setelah Perendaman $20 \%$

\begin{tabular}{lcc}
\multicolumn{1}{c}{ Variabel } & Mean & $\begin{array}{c}\mathrm{P} \\
\text { Value }\end{array}$ \\
\hline $\begin{array}{l}\text { Sebelum Perendaman - Setelah } \\
\text { perendaman 1 }\end{array}$ & 0.0120 & 0.000 \\
$\begin{array}{l}\text { Sebelum Perendaman - Setelah } \\
\text { perendaman 2 }\end{array}$ & 0.0087 & 0.000 \\
$\begin{array}{l}\text { Sebelum Perendaman - Setelah } \\
\text { perendaman 3 }\end{array}$ & 0.0078 & 0.000 \\
$\begin{array}{l}\text { Sebelum Perendaman - Setelah } \\
\text { perendaman 4 }\end{array}$ & 0.0052 & 0.000 \\
$\begin{array}{l}\text { Sebelum Perendaman - Setelah } \\
\text { perendaman 5 }\end{array}$ & 0.0030 & 0.000 \\
\hline
\end{tabular}


Dari tabel 3 dapat dilihat bahwa pada hasil uji $\mathrm{T}(\alpha=0,05)$, berat gigi sebelum dan sesudah perendaman larutan CPP-ACP 20\% selama perendaman $1,2,3,4$ dan 5 menunjukkan perbedaan yang bermakna $(p<0,05)$ antara berat gigi sebelum dilakukan perendaman dan setelah dilakukan perendaman. Berdasarkan hasil di atas dapat disimpulkan bahwa semakin lama waktu perendaman gigi di dalam larutan CPP-ACP $20 \%$ maka semakin tingginya penambahan berat gigi.

Tabel 4 : Hasil Uji T-Paired Berat Gigi Sebelum dan Setelah Perendaman $30 \%$

\begin{tabular}{c|c|c}
\hline Variabel & Mean & $\begin{array}{c}\mathrm{P} \\
\text { Value }\end{array}$ \\
\hline $\begin{array}{c}\text { Sebelum Perendaman - Setelah } \\
\text { perendaman 1 }\end{array}$ & 0.0120 & 0.000 \\
$\begin{array}{c}\text { Sebelum Perendaman - Setelah } \\
\text { perendaman 2 }\end{array}$ & 0.0087 & 0.000 \\
$\begin{array}{c}\text { Sebelum Perendaman - Setelah } \\
\text { perendaman 3 }\end{array}$ & 0.0078 & 0.000 \\
$\begin{array}{c}\text { Sebelum Perendaman - Setelah } \\
\text { perendaman 4 }\end{array}$ & 0.0052 & 0.000 \\
$\begin{array}{c}\text { Sebelum Perendaman - Setelah } \\
\text { perendaman 5 }\end{array}$ & 0.0030 & 0.000 \\
\hline
\end{tabular}

Dari tabel 4 dapat dilihat bahwa pada hasil uji $\mathrm{T}(\alpha=0,05)$, berat gigi sebelum dan sesudah perendaman larutan CPP-ACP 30\% selama perendaman $1,2,3,4$ dan 5 menunjukkan perbedaan yang bermakna $(\mathrm{p}<0,05)$ antara berat gigi sebelum dilakukan perendaman dan setelah dilakukan perendaman. Berdasarkan hasil di atas dapat disimpulkan bahwa semakin lama waktu perendaman gigi di dalam larutan CPP-ACP $30 \%$ maka semakin tingginya penambahan berat gigi

\section{PEMBAHASAN}

Berdasarkan hasil penelitian, diperoleh hasil yaitu terjadinya penambahan berat gigi yang diakibatkan oleh remineralisasi pada perendaman larutan CPP-ACP 10\%, 20\% dan $30 \%$ selama perendaman 1, 2, 3, 4 dan 5. Hasil uji $\mathrm{T}$ satu arah menunjukkan adanya penambahan berat gigi yang bermakna $(\mathrm{p}<0,5)$ pada perendaman $1,2,3,4$ dan 5 .

Penelitian ini menggunakan larutan sediaan CPP-ACP yang mengandung senyawa derivat CPP-ACP yang diaplikasikan sebanyak $1 \mathrm{mg} / 10 \mathrm{ml} \quad(10 \%), \quad 2 \mathrm{mg} / 10 \mathrm{ml}$ (20\%), dan $3 \mathrm{mg} / 10 \mathrm{ml}$ (30\%) pada masingmasing kelompok sampel. Berdasarkan penelitian yang dilakukan mengenai pengujian efektifitas dari pasta yang mengandung CPP-ACP dengan kadar 10\% terhadap kekasaran permukaan enamel secara in vitro, menunjukan bahwa CPP-ACP $10 \%$ mempunyai efek positif terhadap remineralisasi enamel ${ }^{8}$.

Pencegahan karies gigi dari derivat susu bioaktif peptida adalah bentuk kompleks kimia yang mengalir dengan anti-kariogenik. Diantara fungsinya untuk mencegah lesi gigi termasuk menghambat bakteri, meningkat kapasitas penyangga di sekitarnya pelikel gigi, mengurangi demineralisasi enamel dan meningkatkan remineralisasi enamel. ${ }^{6}$.

Remineralisasi awal enamel adalah proses fisiologis normal yang dikenal dalam kedokteran gigi dan penelitian kedokteran gigi. Proses ini dapat terjadi oleh berbagai hal yang dipengaruhi oleh rongga mulut. 
Ketika diaplikasikan pada permukaan gigi dengan lesi awal karies, pasta dengan kandungan $\mathrm{CPP}-\mathrm{ACP}$ dapat mencegah demineralisasi gigi dan meningkatkan remineralisasi enamel serta meningkatkan aktivitas fluoride 9 .

CPP telah terbukti menstabilkan kalsium dan fosfat melalui pembentukan kompleks serta berperan untuk menstabilkan ACP yang memiliki efek aditif. beberapa literatur menunjukkan bahwa CPP-ACP memiliki anti-karies dan efek remineralisasi. Kalsium fosfat pada kompleks ini secara biologis berperan untuk penyerapan dan remineralisasi bawah permukaan lesi pada enamel gigi. ${ }^{2}$.

CPP dapat menstabilkan nanoclusters ACP berbagai phosresidu phoseryl dari mengikat ke CPP nanoclusters dari ACP jenuh untuk mencegah pengendapan ion kalsium dan fosfat serta peningkatan untuk ukuran penting yang diperlukan untuk tahap transformasi. CPP-ACP juga bertindak sebagai media untuk menyimpan kalsium bioavailable dan menjaga fosfat dari kejenuh sehingga memfasilitasi remineralisasi. Studi independen yang diterbitkan sampai saat ini menunjukkan pengaruh dari bahan CPP-ACP dalam menghambat demineralisasi dan meningkatkan remineralisasi enamel dan dentin secara in vivo dan in vitro. Penelitian in vitro dirancang untuk mengevaluasi potensi remineralisasi CPP- ACP yang digunakan pada buatan lesi enamel awal. ${ }^{11}$

\section{KESIMPULAN}

Penelitan yang dilakukan terhadap bahan CPP-ACP dapat meningkatkan remineralisasi gigi. Hal ini berdasarkan penambahan berat gigi selama perendaman pada larutan CPPACP $10 \%$ berturut-turut sebesar $0,0120 \mathrm{~g}$, $0,0087 \mathrm{~g}, 0,0078 \mathrm{~g}, 0,0052 \mathrm{~g}$ dan 0,0030 g. Kemudian pada larutan CPP-ACP 20\% penambahan berturut-turut sebesar $0,0134 \mathrm{~g}$, $0,0097 \mathrm{~g}, 0,0091 \mathrm{~g}, 0,0051 \mathrm{~g}$ dan $0,0026 \mathrm{~g}$ sedangkan pada larutan CPP-ACP $30 \%$ penambahan berturut-turut sebesar $0,0162 \mathrm{~g}$, 0,0105 g, 0,0088 g, 0,0058 g dan 0,0030 g. Dari hasil data tersebut menunjukkan semakin lama pengaplikasian bahan yang mengandung CPP-APC dapat menaikan berat gigi secara bertahap yang sebelumnya sudah mengalami demineralisasi pada gigi.

\section{DAFTAR PUSTAKA}

1. Arteaga, S. Demineralization and Reminer alization: The Battel to KeepTeeth Strong and Healthy. Available from: http://www.dentist ry.com/articles/wdj/print/volume-4/issue9/focus-on-/ [20 Juni 2013].

2. Cross, K.J.; Huq, N.L.; Palamara, J.E.; Perich, J.W.; Reynolds, E.C. 2005. Physicochemical Characterization of Casein Phosphopeptide-Amorphous Calcium Phosphate Nanocomplexes. Journal of Biological Chemistry.

3. Al-Twaijri, S. 2009. Effect of Prophylaxis Pastes Containing Amorphous Calcium Phospate and Flouride on Enamel Bond Streng. BDS, King Saudi University.

4. Walsh, L.J. 2009. Clinical Application of Recaldent Products.

5. Rahiotis, C.; Vougiouklalis, G. 2007. Effect of a CCP-ACP Agent on The Demineralization and Remineralization of Dentine In Vivo. Journal of Dental.

6. Llena, C.; Forner, L.; Baca, P. 2009. Anticariogenicity of Casein Phosphopeptide- 
amorphous Calcium Phosphate. The Journal of Contemporary Dental Practice.

7. Kargul, B.; Altinok, B.; Welbury, R. 2012. The Effect of Casein PhosphopeptideAmorphous Calcium Phospate on Enamel Surface Rehardening. An In Vitro Study. Eur Journal of Pediatrics Dentistry.

8. Makinen, K.K. 2009. Sugar Alcohols, Caries Incidence, and Remineralization of Caries Lesions. International Journal of Dentistry.
9. QIONG ZHANG;Zou, J.:Yang,R.:Zhou, X. 2011 ,Remineralization Effect of Casein Phosphopeptide Amourphous Calcium Phosphate crème on artificial early enamel lession PrimaryTeeth 